Article

\title{
Effect of Intrasilicone Bevacizumab Injection in Diabetic Tractional Retinal Detachment Surgery: A Retrospective Case-Control Study
}

\author{
Seung Kook Baek ${ }^{\mathbb{D}}$, Min-Woo Lee and Young-Hoon Lee * ${ }^{\mathbb{D}}$ \\ Department of Ophthalmology, Konyang University College of Medicine, Daejeon 35365, Korea; \\ backkka@hanmail.net (S.K.B.); bogus1105@gmail.com (M.-W.L.) \\ * Correspondence: astrix001@gmail.com; Tel.: +82-10-3410-0329; Fax: +82-42-600-9250
}

Received: 10 July 2020; Accepted: 23 September 2020; Published: 26 September 2020

\begin{abstract}
Tractional retinal detachment (TRD) causes visual loss in diabetes mellitus patients. Silicone oil can be used as a tamponade to repair retinal detachment; however, intrasilicone injection is challenging. We aimed to evaluate the effect of intrasilicone bevacizumab injection in TRD surgery. This was a single-hospital, retrospective, case-control study of 44 patients (46 eyes). We reviewed medical histories and ophthalmic examination results. We administered silicone oil to 26 eyes (group I), and a combination of silicone oil and intravitreal bevacizumab injection to 20 eyes (group II). The main outcome measures were the logarithm of the minimum angle of resolution (logMAR) visual acuity and central macular thickness. Mean change in logMAR visual acuity was larger $(p=0.029)$ in group II $(-0.99 \pm 0.73)$ than in group I $(-0.56 \pm 0.80), 12$ months postoperatively. Compared to group I, group II exhibited a lower mean $(471.54 \pm 120.14 \mu \mathrm{m}$ vs. $363.40 \pm 59.57 \mu \mathrm{m}$, respectively; $p=0.001)$, and mean change $(-22.39 \pm 203.99 \mu \mathrm{m}$ vs. $-72.40 \pm 139.35 \mu \mathrm{m}$, respectively; $p=0.027)$, in central macular thickness, 1 month postoperatively. Intrasilicone bevacizumab injection immediately after vitrectomy may rapidly reduce central macular thickness and increase final visual acuity. Prospective studies are necessary to demonstrate long-term safety and efficacy.
\end{abstract}

Keywords: bevacizumab; diabetic retinopathy; silicone oil; vitrectomy

\section{Introduction}

Tractional retinal detachment (TRD) in proliferative diabetic retinopathy (PDR) is a major cause of severe visual loss in patients with diabetes mellitus [1]. TRD with recent macular involvement indicates the need for vitrectomy, which remains a challenging procedure despite improvements in surgical instrumentation and techniques, and the development of medication targeting vascular endothelial growth factor (VEGF) [2].

Silicone oil (SO) is transparent, chemically inert, has a low specific gravity and high viscosity, and can be used as a substitute for the vitreous [3]. It has been extensively used as a tamponade for the repair of complicated retinal detachment caused by PDR, proliferative vitreoretinopathy (PVR), and other proliferative vitreoretinal diseases [4,5]. However, neovascularization of the retina or iris can recur even after aggressive vitrectomy combined with an SO tamponade [6]. VEGF plays an important role in the progression of several ocular diseases, and it is associated with neovascularization and increased vascular permeability [7]. However, in the presence of SO, the concentration of medication injected into the posterior segment of the eye is markedly different from that in a vitreous-filled eye, or from that in an eye with fluid infusion following vitrectomy [8]. According to Grzybowski et al. [9], injections into an eye filled with SO can be very challenging. There have been reports of satisfactory results following intravitreal triamcinolone acetonide injection [10] and 
the injection of VEGF inhibitors [11-13] into an SO-filled eye. In addition, Alishiri et al. [14] recently reported favorable results with the simultaneous usage of bevacizumab and $\mathrm{SO}$ following a vitrectomy in diabetic patients with TRD. However, in some cases, after SO injection in PDR surgery, macular edema remains in SO-filled eyes [15]. These results are thought to have an effect on visual acuity after surgery. It is a widely known fact that macular edema is relieved again when anti-VEGF or steroid injection is administered. However, due to safety issues in the SO-filled eye, a clear conclusion has not been established.

The purpose of the present study was to investigate the differences between SO-filled eyes with and without bevacizumab injection after vitrectomy for diabetic patients with TRD. In addition, we would like to consider the effects and advantages of intrasilicone bevacizumab injection immediately after vitrectomy.

\section{Methods}

\subsection{Patients}

This retrospective observational study was approved by the institutional review board (KYUH 2019-05-029) and all procedures adhered to the principles of the Declaration of Helsinki. We reviewed the charts of the PDR patients with TRD that involved the macula, who underwent a vitrectomy from January 2015 to November 2018. Among these patients, we enrolled the patients who completed the surgery with SO injection and SO removal. All patients were followed-up for more than one year. We reviewed the medical history of the enrolled patients and conducted an ophthalmic examination, including measurement of best-corrected visual acuity (BCVA), intraocular pressure (IOP), slit-lamp biomicroscopy, dilated fundus examination, and fundus photography. Optical coherence tomography $(\mathrm{OCT})$ was conducted using a Heidelberg Spectralis ${ }^{\circledR}$ imaging platform (Spectralis; Heidelberg Engineering, Inc., Heidelberg, Germany) prior to surgery. Patients were excluded if they had glaucoma, rhegmatogenous retinal detachment, retinal disease other than diabetic retinopathy (DR), high myopia with an axial length $\geq 27.0 \mathrm{~mm}$, or a history of non-cataract intraocular surgery.

\subsection{Surgical Technique and Postoperative Managements}

All procedures were performed by the same surgeon (YH Lee), consisting primarily of 25-gauge vitrectomy using the Constellation ${ }^{\circledR}$ Vision System (Alcon Laboratories Inc., Fort Worth, Texas, USA). Simultaneous cataract surgery was performed on cataracts with grade 2 or higher, according to the Lens Opacities Classification System (LOCS) III classification, during the first vitrectomy or SO removal. All patients received intravitreal bevacizumab (IVB) injections one day or one week before the surgery. After vitrectomy, the fibrovascular membrane was carefully removed by delamination and segmentation, and retinectomy was performed where the surgeon deemed necessary. Fluid-air exchange, endolaser photocoagulation, and SO (1000 centistokes) tamponade were performed in all cases. At the end of the surgery, $1.25 \mathrm{mg} / 0.05 \mathrm{~mL}$ bevacizumab (Avastin; Genentech, Inc., South San Francisco, CA, USA) was injected into the SO-filled vitreous cavity per the surgeon's discretion. After surgery, all patients self-administered moxifloxacin (Vigamox ${ }^{\circledR}$, Alcon Laboratories, Inc.) and 1\% prednisolone acetate ophthalmic solution (Pred Forte ${ }^{\circledR}$, Allergan, Inc., Irvine, CA, USA) four times daily for one week, followed by levofloxacin and $0.1 \%$ fluorometholone ophthalmic solution (Fluorometholone ${ }^{\circledR}$, Taejoon Pharmaceutical Co., Ltd., Seoul, Korea) for three weeks.

\subsection{Data Collection}

Patients underwent postoperative ophthalmic examinations at 1 day, 1 week, and 1 month before SO removal, as well as at 1 week, 1 month, 2 months, and 12 months after SO removal. BCVA measurement and OCT were conducted during each of these examinations, in order to compare pre- and postoperative BCVA and central macular thickness (CMT) values. BCVA was measured using the Snellen chart, the values of which were converted to logMAR (logarithm of minimum angle of 
resolution) visual acuity (VA) scores for statistical analysis. CMT was defined as the average value of macular thickness in the area (with a 1-mm diameter) around the fovea centralis.

\subsection{Statistical Analysis}

Statistical analyses were performed using SPSS 21.0 (IBM Corp., Armonk, NY, USA; RRID:SCR_002865). Wilcoxon signed-rank tests were used to compare pre- and postoperative values within each group. Fisher's exact tests and Mann-Whitney $U$-tests were used for between-group comparisons. In all cases, the threshold for statistical significance was defined as $p<0.05$.

\section{Results}

\subsection{Patient Demographics and Clinical Characteristics}

We recruited 44 patients (46 eyes) in this study. Of these, 26 eyes received an SO tamponade without IVB injection (group I) and 20 eyes received both an $\mathrm{SO}$ tamponade and IVB injection (group II). There were no statistically significant between-group differences in terms of age, sex, laterality, hypertension, duration of diabetes mellitus, history of panretinal photocoagulation, and number of preoperative IVB injections. However, there was a statistically significant difference in preoperative glycated hemoglobin level (HbA1c) (group I, $8.17 \pm 0.91 \%$ vs. group II, $9.56 \pm 2.61 \% ; p=0.022$ ). No statistically significant difference existed between groups regarding preoperative intraocular pressure (IOP), logMAR VA, or CMT. In terms of the vitrectomy, there was no statistically significant difference in the number of cataracts removed, the volume of SO injected, or the interval between SO injection and removal between groups (Table 1).

Table 1. Patient Demographics and Clinical Characteristics.

\begin{tabular}{cccc}
\hline & Group I (n = 26) & Group II (n = 20) & $p$-Value \\
\hline Age (years) & $54.77 \pm 4.97$ & $54.60 \pm 9.19$ & $0.283^{1}$ \\
Sex (n, \%) & & & \\
Male & $14(53.8 \%)$ & $12(60.0 \%)$ & $0.454^{2}$ \\
Female & $12(46.2 \%)$ & $8(40.0 \%)$ & \\
Laterality (n, \%) & & & \\
Right & $6(23.1 \%)$ & $4(20.0 \%)$ & $0.547^{2}$ \\
Left & $20(76.9 \%)$ & $16(80.0 \%)$ & \\
HTN (n, \%) & $8(30.8 \%)$ & $4(20.0 \%)$ & $0.316^{2}$ \\
Duration of DM (years) & $7.60 \pm 6.02$ & $5.80 \pm 7.90$ & $0.074^{1}$ \\
Preop hemoglobin A1C (\%) & $8.17 \pm 0.91$ & $9.56 \pm 2.61$ & $0.022^{1}$ \\
PRP (n, \%) & $14(53.8 \%)$ & $8(40.0 \%)$ & $0.263^{2}$ \\
Preop IOP (mmHg) & $15.25 \pm 3.34$ & $17.19 \pm 6.41$ & $0.739^{1}$ \\
Preop BCVA (logMAR [Snellen]) & $1.03 \pm 0.69[20 / 214]$ & $1.42 \pm 1.03[20 / 526]$ & $0.245^{1}$ \\
Preop CMT ( $\mu$ m) & $493.92 \pm 219.63$ & $435.80 \pm 125.22$ & $0.723^{1}$ \\
Preop IVB injections (n) & $1.40 \pm 0.82$ & $1.08 \pm 0.27$ & $0.172^{1}$ \\
Postop hemoglobin A1C (\%) & $7.89 \pm 1.76$ & $6.94 \pm 0.33$ & $0.328^{1}$ \\
Combine cataract surgery (n, \%) & $16(61.5 \%)$ & $16(80.0 \%)$ & $0.153^{2}$ \\
SO volume (cc) & $4.22 \pm 0.31$ & $4.46 \pm 0.60$ & $0.368^{1}$ \\
Duration of SO (months) & $4.46 \pm 2.70$ & $4.00 \pm 1.72$ & $0.500^{1}$
\end{tabular}

Values are presented as the mean \pm standard deviation, or a number (\%). Group I received an SO tamponade without IVB injection; group II received an SO tamponade with IVB injection; HTN, hypertension; DM, diabetes mellitus; Preop, preoperative; PRP, panretinal photocoagulation; IOP, intraocular pressure; BCVA, best-corrected visual acuity; logMAR, logarithm of the minimum angle of resolution; CMT, central macular thickness; IVB, intravitreal bevacizumab injection; SO, silicone oil; Postop, postoperative. ${ }^{1}$ Mann-Whitney $U$-test; ${ }^{2}$ Fisher's exact test.

\subsection{Visual Outcomes}

Both groups exhibited improvements in mean logMAR VA 1 month after SO removal (group I, $p=0.031$; group II, $p=0.003$ ) and 12 months postoperatively (group I, $p=0.003$; group II, $p<0.001$ ) compared to the preoperative status. However, there were no statistically significant between-group 
differences in logMAR VA 1 month postoperatively, immediately before SO removal, 1 month after SO removal, or 12 months postoperatively.

Mean change in logMAR VA in group I was $-0.13 \pm 0.77,-0.13 \pm 0.66,-0.42 \pm 0.72$, and $-0.56 \pm 0.80$ at 1 month postoperatively, immediately before SO removal, 1 month after $\mathrm{SO}$ removal, and 12 months postoperatively, respectively. The mean change in logMAR VA in group II, for the same time points, was $-0.38 \pm 0.88,-0.24 \pm 0.76,-0.68 \pm 0.77$, and $-0.99 \pm 0.73$, respectively. There was a statistically significant between-group difference in terms of mean change in logMAR VA at 12 months postoperatively $(p=0.029)$ (Table 2, Figure 1).

Table 2. Between-Group Comparisons of Postoperative Clinical Outcomes.

\begin{tabular}{|c|c|c|c|}
\hline & Group $I^{1}(n=26)$ & Group II ${ }^{1}(n=20)$ & $p$-Value ${ }^{2}$ \\
\hline \multicolumn{4}{|l|}{ BCVA (logMAR [Snellen]) } \\
\hline Preop & $1.03 \pm 0.69[20 / 214]$ & $1.42 \pm 1.03[20 / 526]$ & 0.245 \\
\hline POD 1 month & $0.90 \pm 0.67[20 / 159]$ & $1.04 \pm 0.61[20 / 219]$ & 0.323 \\
\hline Before SO removal & $0.90 \pm 0.46[20 / 159]$ & $1.18 \pm 0.66[20 / 303]$ & 0.240 \\
\hline 1 month after SO removal & $0.61 \pm 0.46 *[20 / 81]$ & $0.74 \pm 0.46 *[20 / 110]$ & 0.137 \\
\hline POD 12 month & $0.47 \pm 0.51 *[20 / 59]$ & $0.43 \pm 0.52 *[20 / 54]$ & 0.720 \\
\hline \multicolumn{4}{|l|}{$\triangle \mathrm{BCVA}(\log \mathrm{MAR})$} \\
\hline POD 1 month & $-0.13 \pm 0.77$ & $-0.38 \pm 0.88$ & 0.266 \\
\hline Before SO removal & $-0.13 \pm 0.66$ & $-0.24 \pm 0.76$ & 0.722 \\
\hline After SO removal & $-0.42 \pm 0.72$ & $-0.68 \pm 0.77$ & 0.304 \\
\hline POD 12 month & $-0.56 \pm 0.80$ & $-0.99 \pm 0.73$ & 0.029 \\
\hline \multicolumn{4}{|l|}{$\mathrm{CMT}(\mu \mathrm{m})$} \\
\hline Preop & $493.92 \pm 219.63$ & $435.80 \pm 125.22$ & 0.723 \\
\hline POD 1 month & $471.54 \pm 120.14$ & $363.40 \pm 59.57 *$ & 0.001 \\
\hline Before SO removal & $382.08 \pm 73.63$ & $351.00 \pm 41.17^{*}$ & 0.399 \\
\hline 1 month after SO removal & $357.31 \pm 84.21$ * & $314.00 \pm 38.53 *$ & 0.092 \\
\hline POD 12 month & $325.00 \pm 77.71 *$ & $298.30 \pm 29.58 *$ & 0.424 \\
\hline \multicolumn{4}{|l|}{$\Delta \mathrm{CMT}(\mu \mathrm{m})$} \\
\hline POD 1 month & $-22.39 \pm 203.99$ & $-72.40 \pm 139.35$ & 0.027 \\
\hline Before SO removal & $-111.85 \pm 202.61$ & $-84.80 \pm 139.98$ & 0.929 \\
\hline After SO removal & $-136.62 \pm 243.70$ & $-121.80 \pm 135.81$ & 0.351 \\
\hline POD 12 month & $-168.92 \pm 239.76$ & $-137.50 \pm 132.67$ & 0.657 \\
\hline
\end{tabular}

Values are presented as the mean \pm standard deviation unless otherwise indicated. Group I received an $\mathrm{SO}$ tamponade without intravitreal bevacizumab injection; group II received an SO tamponade with intravitreal bevacizumab injection; BCVA, best-corrected visual acuity; logMAR, logarithm of the minimum angle of resolution; Preop, preoperative; POD, postoperative day; SO, silicone oil; CMT, central macular thickness. ${ }^{1}$ Wilcoxon signed-rank test. ${ }^{2}$ Mann-Whitney $U$-test. ${ }^{*} p<0.05$ compared to preoperative measurement.

\subsection{Anatomic Outcomes}

Mean CMT tends to decrease over time in both groups. In group I, there were no statistically significant differences in mean CMT from the preoperative status to 1 month postoperatively, or to immediately before SO removal. However, there were statistically significant decreases from the preoperative status to 1 month after SO removal $(p=0.020)$ and to 12 months postoperatively $(p=0.011)$. In group II, there were statistically significant decreases in mean CMT from the preoperative status to 1 month postoperatively ( $p=0.047)$, to immediately before SO removal $(p=0.012)$, to 1 month after SO removal $(p<0.001)$, and to 12 months postoperatively $(p<0.001)$. Additionally, there were statistically significant between-group differences in mean CMT at 1 month postoperatively $(p=0.001)$, but not immediately before SO removal ( $p=0.399), 1$ month after SO removal $(p=0.092)$, or 12 months postoperatively $(p=0.424)$. 


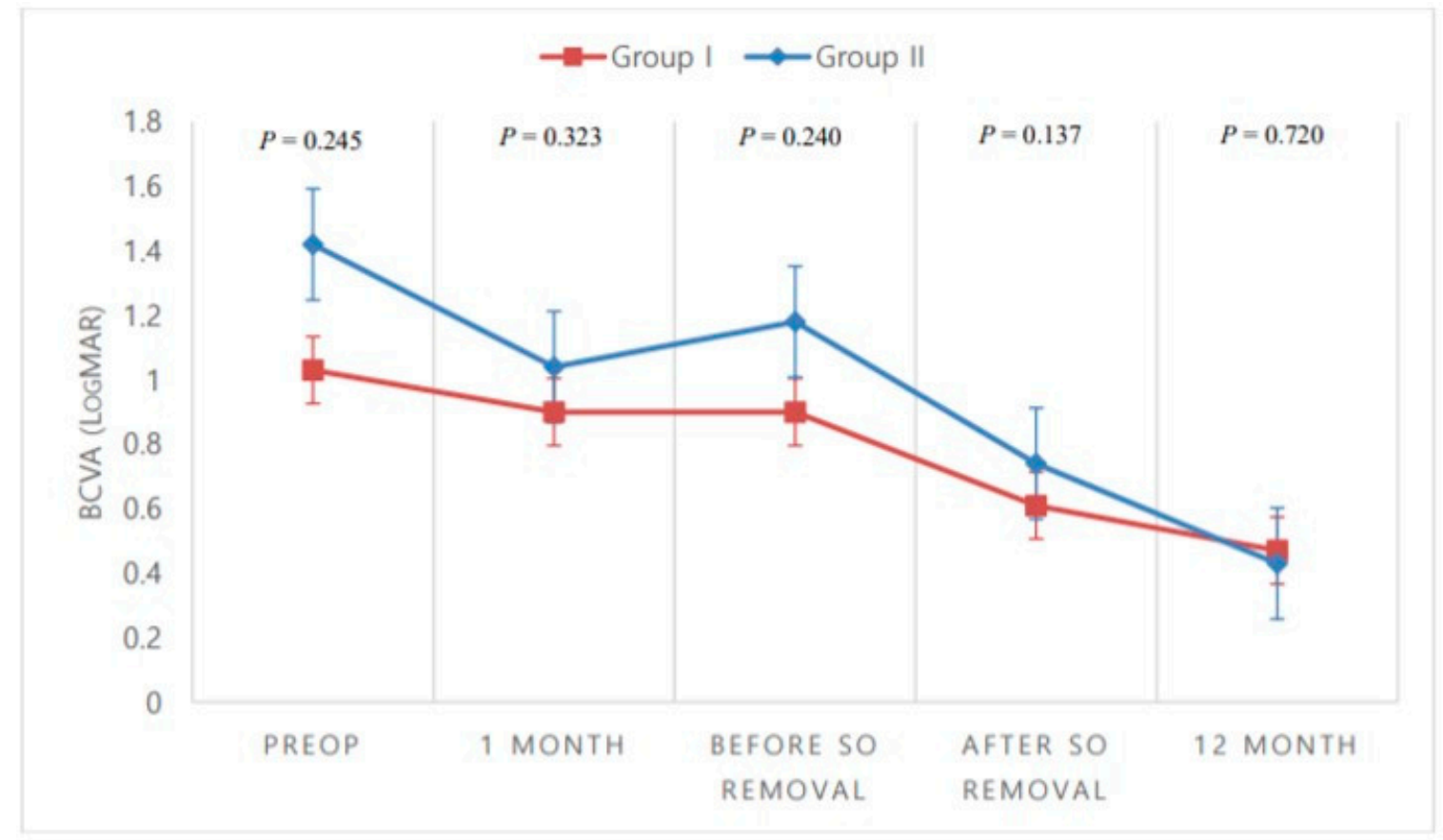

(a)

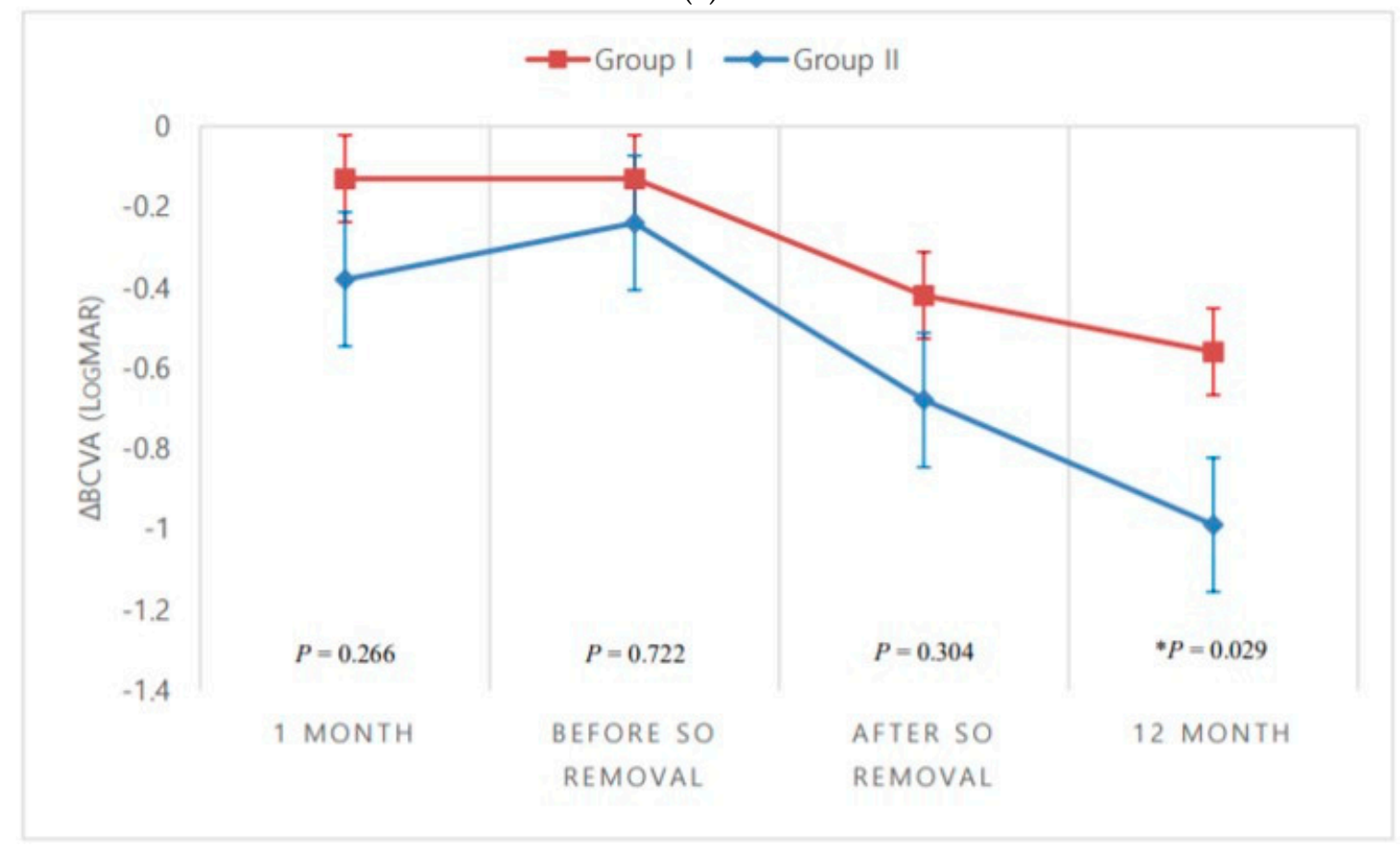

(b)

Figure 1. Between-group comparisons over time. (a) Best-corrected visual acuity (BCVA); (b) Mean change in BCVA from the preoperative (Preop) status. ${ }^{*} p<0.05$, Mann-Whitney $U$-test. SO, silicone oil.

Mean change in CMT also shows that the change increases as time passes in both groups. There was a statistically significant between-group difference in mean change at 1 month postoperatively $(p=0.027)$, but not immediately before SO removal, 1 month after SO removal, or 12 months postoperatively (Table 2, Figure 2). 


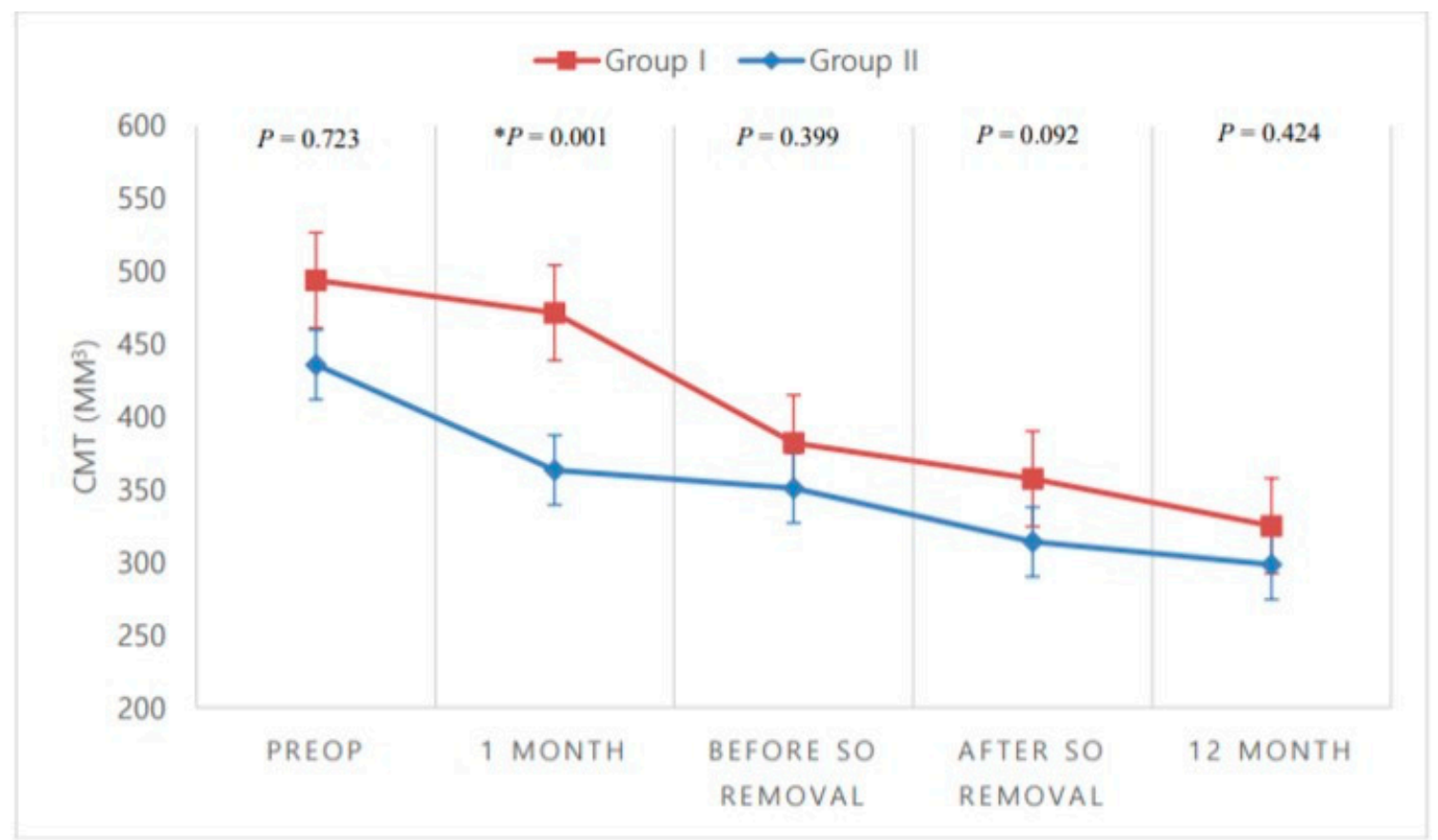

(a)

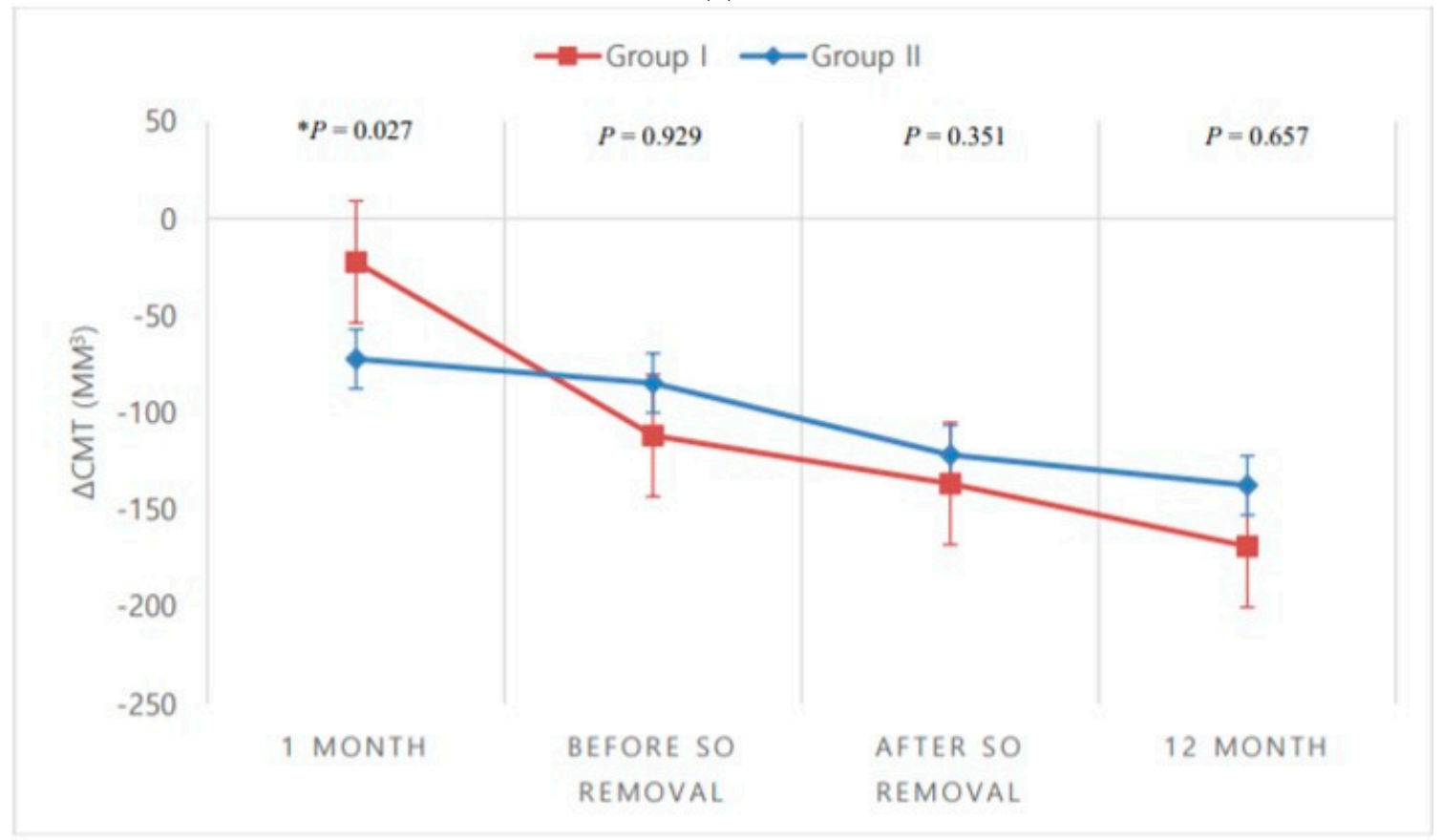

(b)

Figure 2. Between-group comparisons over time. (a) Mean central macular thickness (CMT); (b) Mean change in CMT from the preoperative (Preop) status. ${ }^{*} p<0.05$, Mann-Whitney $U$-test. SO, silicone oil.

\subsection{Postoperative Complications and Other Outcomes}

There was no statistically significant difference in postoperative complications (IOP increase, vitreous hemorrhage, fibrovascular membrane proliferation) and postoperative $\mathrm{HbA} 1 \mathrm{c}$ (12 months postoperatively) between the two groups. However, the number of IVB injections required after SO removal due to macular edema and increasing retinal microhemorrhages was statistically significantly higher in group I than in group II ( $23.1 \%$ vs. $0.0 \%$, respectively; $p=0.025)$ (Table 3$)$. 
Table 3. Postoperative Complications and Other Outcomes.

\begin{tabular}{cccc}
\hline & Group I (n = 26) & Group II (n = 20) & $p$-Value \\
\hline Postop complication & $3(11.5 \%)$ & $2(10.0 \%)$ & $0.627^{1}$ \\
IOP increase & 0 & 2 & \\
Vitreous hemorrhage & 1 & 0 & \\
Fibrovascular membrane proliferation & 2 & 0 & \\
12-month Postop hemoglobin A1c $(\%)$ & $7.89 \pm 1.76$ & $6.94 \pm 0.33$ & $0.328^{2}$ \\
IVB injections after SO removal (n, $\%)$ & $6(23.1 \%)$ & $0(0.0 \%)$ & $0.025^{1}$ \\
\hline
\end{tabular}

Values are presented as the mean \pm standard deviation or a number (\%). Group I received an SO tamponade without IVB injection; group II received an SO tamponade with IVB injection; IOP, intraocular pressure; Postop, postoperative; SO, silicone oil; IVB, intravitreal bevacizumab. ${ }^{1}$ Fisher's exact test; ${ }^{2}$ Mann-Whitney U-test.

\section{Discussion}

TRD is an advanced-stage form of DR that occurs when contractile elements in the vitreous and neovascular growth tissue cause detachment of the neurosensory retina [2,16]. Development of DR, oxidative stress, and retinal ischemia lead to the upregulation of angiogenic factors, particularly VEGF, and several chemokines [17]. IVB injections prior to vitrectomy can reduce active neovascularization [18-20], intraoperative bleeding [21-25], postoperative bleeding [22,23], and duration of surgery $[19,25,26]$ in diabetic patients with TRD. However, the concentration of angiogenic factors, such as VEGF, increase in response to surgical trauma and inflammation in DR patients $[27,28]$. Additionally, in patients with chronic disease such as PDR, inflammatory cytokines are produced in peripheral blood monocular cells (PBMCs), which are associated with VEGF level elevation [29]. High VEGF concentration following surgery may alter the integrity of retinal blood vessels, which may increase postoperative bleeding, persistent macular edema, and retina, iris, and disc neovascularization. In order to reduce this surge in VEGF levels, it has been reported [30-32] that IVB injections administered at the end of the PDR vitrectomy improved the surgical outcome.

The abovementioned results suggest that both preoperative and postoperative IVB injections can be used to reduce postoperative complications. After vitrectomy for TRD, SO is injected in some cases and maintained for a prolonged period. Intravitreal injections are not usually performed in an SO-filled eye, as the effective concentration of injected substances is unpredictable in such eyes [9]. However, triamcinolone acetonide [10,33], dexamethasone implant [34], and bevacizumab [12-14] have been injected in SO-filled eyes to improve surgical outcome.

Our retrospective study was conducted on diabetic patients injected with $\mathrm{SO}$ during surgery for TRD involving the macula, some of whom did not receive bevacizumab injection (group I), and some of whom did (group II). Chronic hyperglycemia causes pathologic changes in the retina and vitreous which leads to progressive deterioration, including TRD [35]. Following vitrectomy, uncontrolled blood glucose levels have been associated with undesirable visual outcomes, such as postoperative bleeding [36]. Thus, careful diabetic control is vital. In the present study, preoperative $\mathrm{HbA1c}$ was statistically significantly higher $(p=0.022)$ in group II $(9.56 \pm 2.61 \%)$ than in group I $(8.17 \pm 0.91 \%)$. Patients were referred to an endocrinologist for postoperative glycemic control. Thereafter, $\mathrm{HbA} 1 \mathrm{c}$ levels of both groups decreased, with no statistically significant difference between groups.

IVB injection 1-14 days prior to surgery has been demonstrated to improve the ease of surgery in complex cases of TRD or vitreous hemorrhage [21]. However, others have reported that TRD progressed after preoperative IVB injection $[37,38]$. In our study, IVB was injected either 1 week or 1 day before TRD surgery, and there was no evidence of fibrovascular membrane proliferation in the surgical field.

In the presence of an SO tamponade, the concentration of medication injected into the posterior segment of the eye is markedly different compared to that in a vitreous-filled eye, or to that in a fluid-infused eye following vitrectomy [8]. SO acts as a barrier to the migration of angiogenic factors, although, due to the buoyancy of $\mathrm{SO}$, the inferior retina remains in contact with aqueous $[5,39,40]$. Angiogenic factors, such as VEGF, can become trapped between silicone 
bubbles and the retina, which can lead to neovascularization or proliferation of preretinal or subretinal fibrous membranes $[39,41]$. In the present study, we observed postoperative complications. In group II, there were no developments of fibrovascular membranes or vitreous hemorrhages; however, there were two cases of increased IOP. In group I, there were two cases of fibrovascular membrane proliferation and one case of vitreous hemorrhage; however, there were no cases of increased IOP. There was no statistically significant difference between the two groups in terms of postoperative complications, and none of the patients required reoperation. We hypothesize that bevacizumab may have accumulated in the meniscus below the SO due to gravity. Any VEGF isolated in SO bubbles may therefore have reacted with the bevacizumab, reducing the likelihood of postoperative fibrovascular membrane proliferation or vitreous hemorrhage. However, further study is needed in order to clarify the exact mechanism involved.

Mean logMAR VA exhibited statistically significant improvement 1 month after SO removal and 12 months after vitrectomy in both groups. Although the mean change of logMAR VA was statistically significantly larger in group II 12 months after surgery, such a between-group comparison is not expected to be of clinical significance due to the variation in cataracts between patients.

In the present study, $61.5 \%$ of patients in group I and $80.0 \%$ of patients in group II underwent cataract removal during the vitrectomy, several patients underwent cataract surgery at the time of SO removal, and we did not exclude patients with preoperative pseudophakia from the study. This variation in cataracts between patients is one of the limitations to our study, as it may have led to selection bias. However, since there was no statistically significant difference between the initial visual acuity and the ratio of simultaneous cataract surgery between the two groups, it is thought that the effect of the selection bias on the study was insignificant. Through prospective studies, it may be necessary to discuss whether intrasilicone bevacizumab injection leads to better visual outcomes under tight control for cataracts.

There may be uncertainty about retinal toxicity when IVB is injected into a SO-filled eye. Salman [13] reported the regression of neovascularization in 12 eyes upon IVB injection $(1.25 \mathrm{mg} / 0.05 \mathrm{~mL})$. Salman also reported a subsequent increase in mean $\log M A R$ VA, and decreasing macular and corneal edema six months after injection. Falavarjani KG et al. [12] injected $2.5 \mathrm{mg} / 0.1 \mathrm{~mL}$ of bevacizumab into SO-filled eyes and observed no retinal toxicity or other complications. Our findings were in line with the abovementioned studies, as we determined that mean logMAR VA improved 12 months after IVB injection in SO-filled eyes. Therefore, we do not consider IVB injection $(1.25 \mathrm{mg} / 0.05 \mathrm{~mL})$ into a SO-filled eye to be toxic to the retina.

$\mathrm{Xu}$ et al. [42] performed vitrectomy and SO injection with IVB $(1.25 \mathrm{mg} / 0.05 \mathrm{~mL})$ in rabbits. Over 24-72 h, the bevacizumab gradually migrated into the vitreous fluid between the SO and the retinal surface, and after $48 \mathrm{~h}$, the visible bevacizumab droplets had disappeared from the oil phase in over $90 \%$ of the eyes. Xu et al. [42] posited that, as a result, bevacizumab distribution was delayed, resulting in stable levels of bevacizumab in the ocular tissues. This could, in turn, lead to fewer systemic physiologic changes and reduced side effects.

In the present study, mean CMT exhibited a statistically significant decrease in both groups 1 month after removal of SO and 12 months after surgery. However, only in group II was there also a statistically significant decrease in mean CMT 1 month after the surgery and immediately before SO removal. Additionally, there were statistically significant between-group differences in mean CMT 1 month postoperatively, and in mean change of CMT 1 month postoperatively. We posit that the reason for this difference was the entrapment of bevacizumab after $\mathrm{SO}$ injection, which prolonged the exposure of the retina to bevacizumab. This would, in turn, prolong the inhibitory and antiangiogenic effect of bevacizumab.

In our study, there was an increased need for IVB injection due to macular edema and retinal microhemorrhage after SO removal in group I when compared with group II $(23.1 \% \mathrm{vs.} 0.0 \%$, $p=0.025)$. This may be explained by the increased pre- and postoperative mean CMT in group I when 
compared with that of group II. Therefore, further study is required to determine whether the need for postoperative IVB injection is truly reduced due to intraoperative IVB injection.

In conclusion, we have demonstrated that intrasilicone bevacizumab injection during TRD surgery in diabetic patients is an effective technique for rapid CMT reduction and improved final visual acuity. Our study therefore supports the role of intrasilicone bevacizumab injection as a valuable option in diabetic TRD surgery. However, future randomized prospective studies are necessary to evaluate the efficacy and safety of this technique.

Author Contributions: Design and conduct of the study, S.K.B., Y.-H.L.; Collection of data, S.K.B., Y.-H.L.; Analysis and interpretation of data, S.K.B., Y.-H.L.; Writing the article, S.K.B., Y.-H.L.; Critical revision of the article, S.K.B., Y.-H.L.; Final approval of the article, S.K.B., M.-W.L., Y.-H.L. All authors have read and agreed to the published version of the manuscript.

Funding: This research was funded by the Korea Health Technology R\&D Project through the Korea Health Industry Development Institute (KHIDI), funded by the Ministry of Health \& Welfare, Republic of Korea, grant number HI17C2412.

Conflicts of Interest: The authors declare no conflict of interest.

\section{References}

1. Fong, D.S.; Ferris, F.L., III; Davis, M.D.; Chew, E.Y. Causes of severe visual loss in the early treatment diabetic retinopathy study: ETDRS report no. 24. Early Treatment Diabetic Retinopathy Study Research Group. Am. J. Ophthalmol. 1999, 127, 137-141. [CrossRef]

2. Stewart, M.W.; Browning, D.J.; Landers, M.B. Current management of diabetic tractional retinal detachments. Indian J. Ophthalmol. 2018, 66, 1751-1762. [CrossRef]

3. Abu El-Asrar, A.M.; Al-Bishi, S.M.; Kangave, D. Outcome of temporary silicone oil tamponade in complex rhegmatogenous retinal detachment. Eur. J. Ophthalmol. 2003, 13, 474-481. [CrossRef]

4. Scott, I.U.; Flynn, H.W., Jr.; Murray, T.G.; Smiddy, W.E.; Davis, J.L.; Feuer, W.J. Outcomes of complex retinal detachment repair using 1000- vs 5000-centistoke silicone oil. Arch. Ophthalmol. 2005, 123, $473-478$. [CrossRef]

5. Castellarin, A.; Grigorian, R.; Bhagat, N.; Del Priore, L.; Zarbin, M.A. Vitrectomy with silicone oil infusion in severe diabetic retinopathy. Br. J. Ophthalmol. 2003, 87, 318-321. [CrossRef] [PubMed]

6. Yeh, P.T.; Yang, C.M.; Lin, Y.C.; Chen, M.S.; Yang, C.H. Bevacizumab pretreatment in vitrectomy with silicone oil for severe diabetic retinopathy. Retina 2009, 29, 768-774. [CrossRef]

7. Ferrara, N. Vascular endothelial growth factor: Basic science and clinical progress. Endocr. Rev. 2004, 25, 581-611. [CrossRef]

8. Hegazy, H.M.; Kivilcim, M.; Peyman, G.A.; Unal, M.H.; Liang, C.; Molinari, L.C.; Kazi, A.A. Evaluation of toxicity of intravitreal ceftazidime, vancomycin, and ganciclovir in a silicone oil-filled eye. Retina 1999, 19, 553-557. [CrossRef]

9. Grzybowski, A.; Told, R.; Sacu, S.; Bandello, F.; Moisseiev, E.; Loewenstein, A.; Schmidt-Erfurth, U. 2018 update on intravitreal injections: Euretina Expert Consensus Recommendations. Ophthalmologica 2018, 239, 181-193. [CrossRef]

10. Ahmadieh, H.; Feghhi, M.; Tabatabaei, H.; Shoeibi, N.; Ramezani, M.; Mohebbi, M.R. Triamcinolone acetonide in silicone-filled eyes as adjunctive treatment for proliferative vitreoretinopathy: A randomized clinical trial. Ophthalmology 2008, 115, 1938-1943. [CrossRef]

11. Chhablani, J.; Narayanan, R. Anti-VEGF therapy in a silicone oil-filled myopic eye with choroidal neovascularisation. BMJ Case Rep. 2015, bcr2014208663. [CrossRef] [PubMed]

12. Falavarjani, K.G.; Modarres, M.; Nazari, H. Therapeutic effect of bevacizumab injected into the silicone oil in eyes with neovascular glaucoma after vitrectomy for advanced diabetic retinopathy. Eye 2010, 24, 717-719. [CrossRef] [PubMed]

13. Salman, A.G. Intrasilicone bevacizumab injection for iris neovascularization after vitrectomy for proliferative diabetic retinopathy. Ophthalmic Res. 2013, 49, 20-24. [CrossRef]

14. Alishiri, A.; Naderi, M.; Jadidi, K.; Mosavi, S.A. Efficacy of simultaneous usage of bevacizumab and silicone oil injection after vitrectomy in diabetic tractional retinal detachment. Razavi Int. J. Med. 2017, e43217. [CrossRef] 
15. Rashad, M.A.; Mohamed, A.A.A.; Ahmed, A.I. Value of optical coherence tomography in the detection of macular pathology before the removal of silicone oil. Clin. Ophthalmol. 2016, 10, 121-135. [CrossRef]

16. Iyer, S.S.R.; Regan, K.A.; Burnham, J.M.; Chen, C.J. Surgical management of diabetic tractional retinal detachments. Surv. Ophthalmol. 2019, 64, 780-809. [CrossRef]

17. Aiello, L.P.; Avery, R.L.; Arrigg, P.G.; Keyt, B.A.; Jampel, H.D.; Shah, S.T.; Pasquale, L.R.; Thieme, H.; Iwamoto, M.A.; Park, J.E.; et al. Vascular endothelial growth factor in ocular fluid of patients with diabetic retinopathy and other retinal disorders. N. Engl. J. Med. 1994, 331, 1480-1487. [CrossRef]

18. Chen, E.; Park, C.H. Use of intravitreal bevacizumab as a preoperative adjunct for tractional retinal detachment repair in severe proliferative diabetic retinopathy. Retina 2006, 26, 699-700. [CrossRef]

19. Rizzo, S.; Genovesi-Ebert, F.; Di Bartolo, E.; Vento, A.; Miniaci, S.; Williams, G. Injection of intravitreal bevacizumab (Avastin) as a preoperative adjunct before vitrectomy surgery in the treatment of severe proliferative diabetic retinopathy (PDR). Graefes Arch. Clin. Exp. Ophthalmol. 2008, 246, 837-842. [CrossRef]

20. Yeoh, J.; Williams, C.; Allen, P.; Buttery, R.; Chiu, D.; Clark, B.; Essex, R.; McCombe, M.; Qureshi, S.; Campbell, W.G. Avastin as an adjunct to vitrectomy in the management of severe proliferative diabetic retinopathy: A prospective case series. Clin. Exp. Ophthalmol. 2008, 36, 449-454. [CrossRef]

21. Hattori, T.; Shimada, H.; Nakashizuka, H.; Mizutani, Y.; Mori, R.; Yuzawa, M. Dose of intravitreal bevacizumab (Avastin) used as preoperative adjunct therapy for proliferative diabetic retinopathy. Retina 2010, 30, 761-764. [CrossRef] [PubMed]

22. Ahmadieh, H.; Shoeibi, N.; Entezari, M.; Monshizadeh, R. Intravitreal bevacizumab for prevention of early postvitrectomy hemorrhage in diabetic patients: A randomized clinical trial. Ophthalmology 2009, 116, 1943-1948. [CrossRef] [PubMed]

23. Lo, W.R.; Kim, S.J.; Aaberg, T.M., Sr.; Bergstrom, C.; Srivastava, S.; Yan, J.; Martin, D.F.; Hubbard, G.B., III. Visual outcomes and incidence of recurrent vitreous hemorrhage after vitrectomy in diabetic eyes pretreated with bevacizumab (Avastin). Retina 2009, 29, 926-931. [CrossRef]

24. Da R Lucena, D.; Ribeiro, J.A.S.; Costa, R.A.; Barbosa, J.C.; Scott, I.U.; de Figueirido-Pontes, L.L.; Jorge, R. Intraoperative bleeding during vitrectomy for diabetic tractional retinal detachment with versus without preoperative intravitreal bevacizumab (IBeTra study). Br. J. Ophthalmol. 2009, 93, 688-691. [CrossRef]

25. Oshima, Y.; Shima, C.; Wakabayashi, T.; Kusaka, S.; Shiraga, F.; Masahito, O.; Tano, Y. Microincision vitrectomy surgery and intravitreal bevacizumab as a surgical adjunct to treat diabetic traction retinal detachment. Ophthalmology 2009, 116, 927-938. [CrossRef]

26. di Lauro, R.; De Ruggiero, P.; di Lauro, R.; di Lauro, M.T.; Romano, M.R. Intravitreal bevacizumab for surgical treatment of severe proliferative diabetic retinopathy. Graefes Arch. Clin. Exp. Ophthalmol. 2010, 248, 785-791. [CrossRef]

27. Simo, R.; Carrasco, E.; Garcia-Ramirez, M.; Hernandez, C. Angiogenic and antiangiogenic factors in proliferative diabetic retinopathy. Curr. Diabetes. Rev. 2006, 2, 71-98. [CrossRef]

28. Funatsu, H.; Yamashita, H.; Ikeda, T.; Mimura, T.; Eguchi, S.; Hori, S. Vitreous levels of interleukin-6 and vascular endothelial growth factor are related to diabetic macular edema. Ophthalmology 2003, 110, 1690-1696. [CrossRef]

29. Gorenjak, V.; Vance, D.R.; Petrelis, A.M.; Stathopoulou, M.G.; Dadé, S.; Shamieh, S.E.; Helena, M.; Masson, C.; Lamont, J.; Fitzgerald, P.; et al. Peripheral blood mononuclear cells extracts VEGF protein levels and VEGF mRNA: Associations with inflammatory molecules in a healthy population. PLoS ONE 2019, 14, e0220902. [CrossRef]

30. Park, D.H.; Shin, J.P.; Kim, S.Y. Intravitreal injection of bevacizumab and triamcinolone acetonide at the end of vitrectomy for diabetic vitreous hemorrhage: A comparative study. Graefes Arch. Clin. Exp. Ophthalmol. 2010, 248, 641-650. [CrossRef]

31. Cheema, R.A.; Mushtaq, J.; Al-Khars, W.; Al-Askar, E.; Cheema, M.A. Role of intravitreal bevacizumab (Avastin) injected at the end of diabetic vitrectomy in preventing postoperative recurrent vitreous hemorrhage. Retina 2010, 30, 1646-1650. [CrossRef] [PubMed]

32. Ahn, J.; Woo, S.J.; Chung, H.; Park, K.H. The effect of adjunctive intravitreal bevacizumab for preventing postvitrectomy hemorrhage in proliferative diabetic retinopathy. Ophthalmology 2011, 118, 2218-2226. [CrossRef] [PubMed]

33. Byon, I.S.; Lee, J.E.; Oum, B.S. Intravitreal injection of triamcinolone acetonide in vitrectomy with silicone oil placement. J. Korean Ophthalmol. Soc. 2006, 47, 1298-1305. 
34. Esenulku, C.M.; Gunay, M. Location of a dexamethasone implant at the macula after intravitreal injection in a silicone oil-filled eye. Case Rep. Ophthalmol. Med. 2006, 5107652. [CrossRef]

35. Kroll, P.; Rodrigues, E.B.; Hoerle, S. Pathogenesis and classification of proliferative diabetic vitreoretinopathy. Ophthalmologica 2007, 221, 78-94. [CrossRef]

36. Sato, K.; Tsuboi, K.; Nakashima, H.; Emi, K. Characteristics of cases with postoperative vitreous hemorrhage after 25-gauge vitrectomy for repair of proliferative diabetic retinopathy. Graefes Arch. Clin. Exp. Ophthalmol. 2017, 255, 665-671. [CrossRef]

37. Moradian, S.; Ahmadieh, H.; Malihi, M.; Soheilian, M.; Dehghan, M.H.; Azarmina, M. Intravitreal bevacizumab in active progressive proliferative diabetic retinopathy. Graefes Arch. Clin. Exp. Ophthalmol. 2008, 246, 1699-1705. [CrossRef]

38. Arevalo, J.F.; Maia, M.; Flynn, H.W., Jr.; Saravia, M.; Avery, R.L.; Wu, L.; Eid Farah, M.; Pieramici, D.J.; Berrocal, M.H.; Sanchez, J.G. Tractional retinal detachment following intravitreal bevacizumab (Avastin ${ }^{\circledR}$ ) in patients with severe proliferative diabetic retinopathy. Br. J. Ophthalmol. 2008, 92, 213-216. [CrossRef]

39. Pearson, R.V.; McLeod, D.; Gregor, Z.J. Removal of silicone oil following diabetic vitrectomy. Br. J. Ophthalmol. 1993, 77, 204-207. [CrossRef]

40. Barca, F.; Caporossi, T.; Rizzo, S. Silicone oil: Different physical properties and clinical applications. BioMed Res. Int. 2014, 502143. [CrossRef]

41. Yorston, D.; Wickham, L.; Benson, S.; Bunce, C.; Sheard, R.; Charteris, D. Predictive clinical features and outcomes of vitrectomy for proliferative diabetic retinopathy. Br. J. Ophthalmol. 2008, 92, 365-368. [CrossRef] [PubMed]

42. Xu, Y.; You, Y.; Du, W.; Zhao, C.; Li, J.; Mao, J.; Chen, H.; Cheng, L. Ocular pharmacokinetics of bevacizumab in vitrectomized eyes with silicone oil tamponade. Investig. Ophthalmol. Vis. Sci. 2012, 53, 5221-5226. [CrossRef] [PubMed]

(C) 2020 by the authors. Licensee MDPI, Basel, Switzerland. This article is an open access article distributed under the terms and conditions of the Creative Commons Attribution (CC BY) license (http://creativecommons.org/licenses/by/4.0/). 